\title{
Tobacco Usage in France: An Epidemiological Study
}

\author{
Ernst L. Wynder, ${ }^{*}$ Margaret H. Mushinski, * \\ Steven D. Stellman, $\dagger$ and Patrick Choay $\ddagger$
}

\author{
*Division of Epidemiology, American Health Foundation, 320 East 43rd Street, New \\ York, New York 10017, †American Cancer Society, 777 Third Avenue, New York, New \\ York 10017, and $\ddagger$ Institut Choay, 46 Avenue, Theophile Gautier, 75016 Paris, France
}

\begin{abstract}
A survey of tobacco and alcohol consumption was conducted among 3,453 noninstitutionalized men and women in 65 departements in France. Over four-fifths of the men and half of the women surveyed had smoked cigarettes. Men were far more likely than women to have stopped smoking, especially older men in higher social classes. Fifty-five percent of the men smoked cigarettes made with black tobacco (Gauloises, Gitanes), while women preferred blond tobacco products. Younger smokers of both sexes preferred filtered cigarettes, while older respondents smoked nonfiltered ones. Filter usage among men, but not women, increased with education. Inhalation was more prevalent among men than women, among the young than the old, and among the more educated than the less educated. "Drooping'" or carrying a lighted cigarettes in the mouth without inhaling, was a practice more common in older, less educated male smokers. These data also provide some evidence in support of the hypothesis that black tobacco, with its higher $\mathrm{pH}$, provides unprotonated nicotine which is easily absorbed by oral mucosa, thus making deep inhalation of the smoke less important to the smoker. The observed differences between the smoking practices of the French and those in the United States and United Kingdom along with the relatively higher alcohol consumption noted throughout France, may partially explain the lower rates of lung cancer and higher rates of larynx, esophagus, and oral cavity cancer found in French men.
\end{abstract}

\section{INTRODUCTION}

For at least 20 years, lung cancer has been the most common neoplastic disease in many Western nations, in line with increases in per capita cigarette consumption. France, however, retains a relatively low lung cancer rate while rates of certain other tobacco-related cancers, most notably those of the mouth, larynx, and esophagus, are unusually high among French men (Fig. 1) $(10,11)$. The lack of congruence in mortality rates of these four cancers among the United Kingdom, the United States, and France cannot be explained by differences in tobacco consumption alone. We hypothesize that the method of cigarette smoking plus alcohol consumption contribute to a partial explanation of the international variation in rates as well as the differences in the rates between the sexes.

The popularity of cigarettes made with black tobacco and the habit of holding a lit cigarette in the mouth without inhaling constitute major deviations between the smoking habits of the French and those of the United States, United Kingdom, and other nationalities. These and other differences were examined in a retrospective study of the smoking and drinking habits of a sample of the French population. Interest was focused not only on the various forms of tobacco used but also on inhalation practices, which are thought to be related to $\mathrm{pH}$ levels of black or blond tobacco smoke. An additional objective was to investigate the 

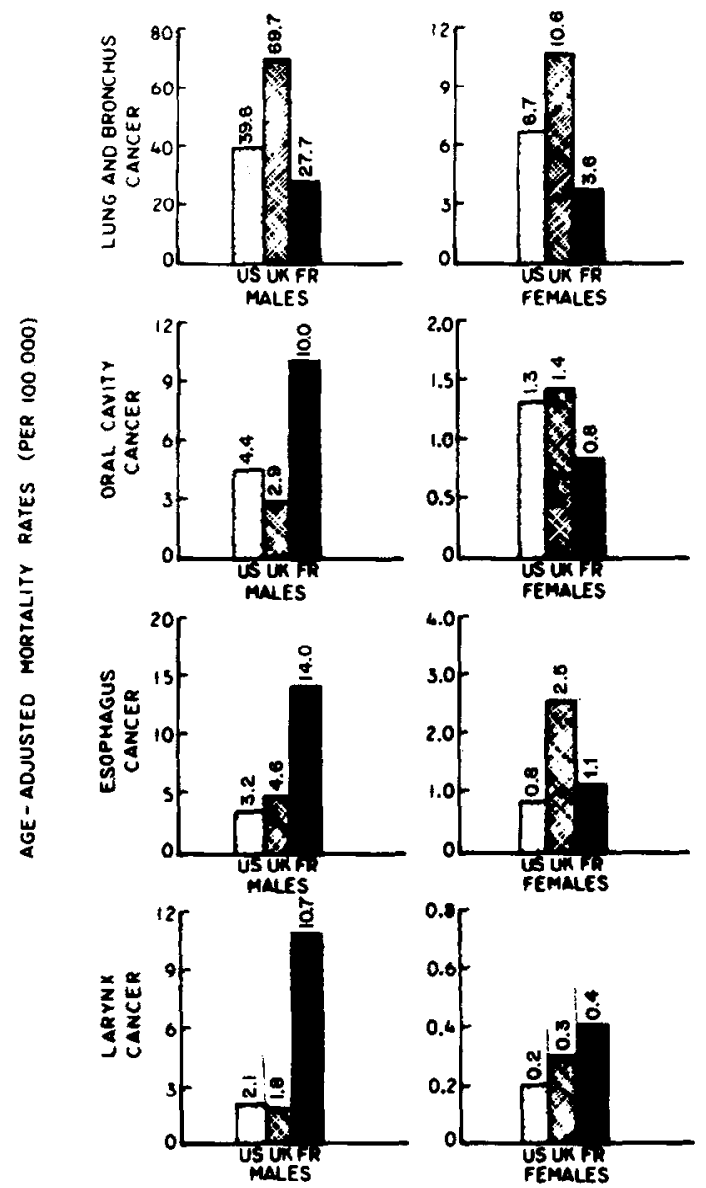

FIG. 1. Mortality rates for selected cancer sites, by sex, in U.S., U.K., and France.

relationship between tobacco usage in France and various demographic variables such as sex, residence, and socioeconomic status.

It was anticipated that such a survey would not only provide a good description of the French smoking pattern, but also aid in a rationalization of the varying rates of tobacco-related cancers. Such data could help to make projections as to how changes in smoking habits might lead to changes in rates of these diseases in France.

\section{MATERIAL AND METHODS}

Data were collected by means of a French version of the standardized Comprehensive Tobacco Questionnaire used by the American Health Foundation in the United States for the past 10 years (17). A team of interviewers experienced in medical/scientific research, were specially trained in administering and coding the questionnaires. The questionnaires were checked for consistency, clarity, and completeness by one of the collaborators (P. C.) who also served as consultant to the interviewers in the field. 
Between June and September 1976, more than 4,000 persons, between 20 and 80 years of age, were randomly selected and screened for study acceptance and availability as they left factories, universities, business offices, and stores. A total of 3,453 persons fit the study criteria; fewer than $10 \%$ of the persons approached by each interviewer refused to be interviewed, and approximately $8 \%$ of the potential interviewees had a condition ${ }^{1}$ which precluded participation in the study.

Although no attempt was made to obtain a geographical probability sample, the demographic characteristics of the study group were sufficiently similar to those of the general French population to permit generalization (Table 1). The major regions of France with the greatest population density, except strictly tourist areas, were included in the survey. That is, of the possible 95 administrative départements in France, 65 départements were represented in the study. The following regions contributed at least $3 \%$ of study cases: Marne (12.1\%) Paris (12.0\%), Hauts de Seine (11.1\%), Var (10.0\%), Landes (9.2\%), Essone (7.9\%), Gironde (3.6\%), and Manche (3.0\%). Thus, both rural and urban area residents were questioned. Because $47 \%$ of the adult men in France smoke compared with $20 \%$ of adult French women $(3,12)$, close to two males for each woman were included in the study $(2,163$ and 1,290 , respectively).

\section{RESULTS}

\section{Background Data}

For each sex, approximately one-third of the subjects ranged in age from 20 to 39 , one-third from 40 to 54 , and one-third above 55 years of age. All but $7 \%$ of the respondents were native born; 59\% were born in urban areas, and $62.8 \%$ spent their adult lives in urban areas. Of the 246 immigrated to France, 85 (35\%) had done so before the age of 16 , the average age at which smoking began. Thus, the great majority of smokers began smoking when living in France, presumably with locally available tobacco products, and adopting local smoking habits.

Approximately equal proportions of men had completed $0-6,7-9,11-12$, and $13+$ years of school. For women, $60 \%$ had $7-12$ years of schooling, with $20 \%$ each above and below this level. Seventy-nine percent of the men $(1,706)$ were employed at the time of the survey compared with $54 \%$ of the women (693); almost one-third of the women indicated housewife as their occupation.

\section{Types of Tobacco Products Used}

Respondents were asked which specific combination of cigarettes, cigars, and pipes they used and whether they had ever used snuff or chewing tobacco. Cigarettes were "ever" smoked by $82 \%$ of men and $56 \%$ of women, either alone or in combination with cigars and pipes. Sixty-six of the 2,163 men (3\%) had smoked pipes exclusively, and $4.3 \%$ smoked cigars or pipes exclusive of cigarettes. Except for 17 women who indicated use of cigars or pipes in addition to cigarettes, women either smoked cigarettes or did not smoke at all. As expected, pipes were smoked more often by older men ( $4.5 \%$ at ages $55-89)$ than younger men $(1.2 \%$ at ages $20-39$ ). Chewing tobacco had been used by 40 men (1.9\%) and only one

\footnotetext{
${ }^{1}$ History of alcoholism or a psychiatric condition which might affect reliability of response.
} 
WYNDER ET AL.

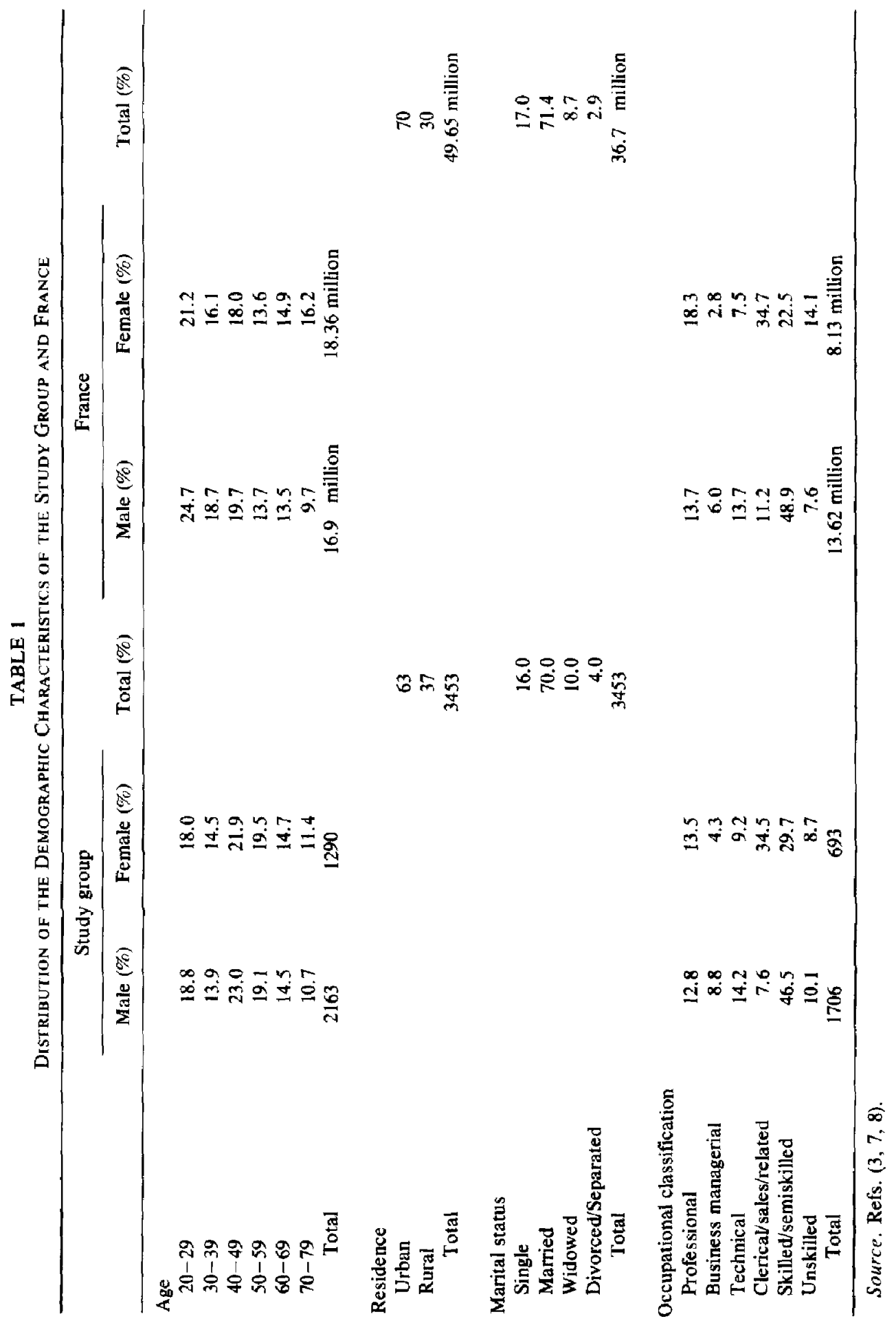


woman. Three-fourths of the men who had chewed tobacco were 60 years old or over. Snuff use, either by nose or mouth, was acknowledged by $326(16 \%)$ of the men and $82(7 \%)$ of the women.

\section{Current Smoking Status}

The study defined nonsmokers as persons who had never regularly smoked any tobacco product; exsmokers as persons who had previously smoked cigarettes regularly, but had not smoked for at least one year prior to interview. Current cigarette smokers were divided into those who had been smoking for 9 years or less (termed recent smokers) and those who had smoked for at least 10 years (long-term smokers); the remainder were persons who had never smoked cigarettes but who had ever smoked cigars and/or pipes (Table 2).

Smoking status varied markedly with sex, age, and social status. Women were more than three times as likely as men to be nonsmokers (44 versus $14 \%$ ), and among the smokers, men were 1.25 times as likely to be current long-term smokers (69 versus $55 \%$ ) than women. More than twice as many women than men were categorized as recent smokers ( 20 versus $9 \%$ ). A slightly higher proportion of the female "ever smokers" had given up the habit than the males in the study (25 versus $22 \%$ ).

The proportion of men who had never smoked was between 10 and $20 \%$ in all age groups: $17 \%$ below age 30 , dropping to $12 \%$ at ages $60-69$, and increasing to $14 \%$ above age 70 . Between ages 30 and 70 , male smoking habits vary little with age, except for a slight increase in smoking cessation as the males grow older.

As in other countries, the smoking patterns differed between the men and women studied. That is, the proportion of female "never smokers" increased steadily from $27 \%$ at ages $20-29$ to $78 \%$ above age 60 . The proportion of long-term smokers increased steadily between 20 and 40, slightly between 41 and 50 , and decreased much more sharply than for males after 50 years of age. In all age groups, among those classified as long-term smokers, proportionately fewer of the women than the men smoked nonfiltered cigarettes.

TABLE 2

Tobacco Usage of French Men and Women INTERVIEWED BETWEEN JUNE AND SEPTEMBER 1976

\begin{tabular}{|c|c|c|c|c|}
\hline & \multicolumn{2}{|c|}{ Males } & \multicolumn{2}{|c|}{ Females } \\
\hline & $N$ & $\%$ & $N$ & $\%$ \\
\hline \multicolumn{5}{|l|}{ Smoking status } \\
\hline Never smoked & 301 & 13.9 & 570 & 44.2 \\
\hline Ever smokers (cigarettes only) & 1769 & 81.8 & 719 & 55.7 \\
\hline Cigar/pipe smokers & 93 & 4.3 & 1 & 0.1 \\
\hline Total & 2163 & 100.0 & 1290 & 100.0 \\
\hline \multicolumn{5}{|l|}{ Cigarette smoking history } \\
\hline Exsmokers & 386 & 21.8 & 182 & 25.3 \\
\hline Recent smokers & 165 & 9.3 & 144 & 20.0 \\
\hline Long-term smokers & 1218 & 68.9 & 393 & 54.7 \\
\hline Total & 1769 & 100.0 & 719 & 100.0 \\
\hline
\end{tabular}


On average, men began smoking approximately $2-4$ years earlier than women and for both sexes a trend toward initiating the habit at younger ages is apparent. The difference between the sexes in average age-began-smoking diminishes to 1.5 years for the youngest members of the survey, 16.4 years old for men versus 17.9 years for women. The greatest difference is apparent for the older members of the survey where men began to smoke at 18.8 and women at 25.4. Thus in France, as in other countries, smoking habits of young women are becoming more similar to those of their male counterparts (Table 3).

Smoking habits also varied with socioeconomic status. Among the men, unskilled workers had the highest rate of current long-term smokers (72\%), and professionals the lowest $(48 \%)$. The reverse was true for exsmokers: $25 \%$ of professionals, $16 \%$ of skilled and semiskilled, and $8 \%$ of unskilled; similarly for pipe/cigar users. This situation was reversed for women, however. The largest proportions of nonsmokers were found in the skilled (55\%), semiskilled (49\%), and unskilled (45\%) groups and the lowest (27\%) among professionals. Professional and businesswomen were more likely to be long-term smokers than skilled or unskilled workers.

\section{Quantity Smoked per Day}

Men consistently smoked more cigarettes than women. While the male-female differences remain about the same across ages, the absolute quantities smoked drop by approximately $25 \%$ in the oldest group-a possible economic factor, or the fact that heavier smokers have died before reaching old age. Below age 55, men smoke approximately one pack each day, and women smoke three-fourths of a pack, or 15 cigarettes per day (Table 3). These data are also in accord with consumption patterns in the United States (17).

Clearly, cigarette smoking among the lower socioeconomic classes in France is

TABLE 3

Selected Characteristics of Current long-Term

French SMOKers ${ }^{n}$ By AGE AND SEX

\begin{tabular}{|c|c|c|c|c|c|c|c|c|}
\hline \multirow[b]{2}{*}{ Age } & \multicolumn{2}{|c|}{$\begin{array}{l}\text { Age began } \\
\text { smoking }\end{array}$} & \multicolumn{2}{|c|}{$\begin{array}{l}\text { Years smoked } \\
\text { nonfitters }\end{array}$} & \multicolumn{2}{|c|}{$\begin{array}{l}\text { Years smoked } \\
\text { filters }\end{array}$} & \multicolumn{2}{|c|}{$\begin{array}{l}\text { Quantity smoked } \\
\text { per day }\end{array}$} \\
\hline & Average & $N$ & Average & $N$ & Average & $N$ & Average & $N$ \\
\hline \multicolumn{9}{|l|}{ Males } \\
\hline $20-39$ & 16.4 & 287 & 14.7 & 191 & 11.7 & 160 & 21.1 & 287 \\
\hline $40-54$ & 17.8 & 511 & 26.0 & 427 & 15.4 & 261 & 20.8 & 511 \\
\hline $55-89$ & 18.8 & 420 & 41.5 & 404 & 17.4 & 133 & 16.2 & 420 \\
\hline \multicolumn{9}{|l|}{ Females } \\
\hline $20-39$ & 17.9 & 114 & 12.9 & 40 & 13.1 & 98 & 15.7 & 114 \\
\hline $40-54$ & 22.0 & 203 & 18.2 & 106 & 17.8 & 172 & 16.4 & 203 \\
\hline $55-89$ & 25.4 & 76 & 28.0 & 54 & 21.7 & 55 & 11.9 & 76 \\
\hline
\end{tabular}

${ }^{a}$ Current smokers of cigarettes who have smoked for at least 10 years.

${ }^{b}$ Includes those who have smoked nonfilter for at least one year.

' Includes those who have smoked filters for at least one year. 
encouraged in men and discouraged in women. In fact, until 1976, free cigarettes were routinely distributed to males during National Service. However, among the higher classes, women have "achieved" acceptance of smoking, along with their successful entrance into traditionally held male roles, while men have advanced to the point of large-scale cessation, as in the United States (18).

\section{Blond versus Black Tobacco}

Cigarette brands were coded according to a list prepared from the French government's Liste Officielle des Tabacs; differentiation into blond or black tobacco was made possible through supplementary marketing information.

The sexes differed greatly in their preference for both filtered and nonfiltered cigarettes and for black or blond tobacco. Men who listed a preferred brand chose nonfiltered brands over filtered ( 58 to $42 \%$ ) while women preferred filters ( 77 to $23 \%$ ); men overwhelmingly preferred black tobacco to blond (86 to 14\%) while women slightly preferred blond ( 51 to $49 \%$ ). The black tobacco brands most often smoked, whether by filter or nonfilter smokers, were Gauloises (the brand provided during conscription), followed by Gitanes. These two brands accounted for $58 \%$ of the market share of all cigarettes among men, and $48.6 \%$ for women. Smokers of black nonfiltered cigarettes tended to be older than either the black or blond filter users; of men who smoked nonfilter Gauloises, $44 \%$ were aged 55 and above, while $42 \%$ of nonfilter Gitanes smokers were aged 39 and below.

\section{Brand and Education}

Males. There is an observable gradient with education in choice of tobacco product (Fig. 2). The percentage of persons using blond filtered cigarettes increased from $5.4 \%$ among those with 6 years or less of education to $20 \%$ among those with at least 15 years of formal schooling; an obvious reflection that bettereducated, more affluent groups can afford the more expensive imported blond brands. Similar increases were evident with black filtered cigarettes and the trend reverses for black and blond nonfilter cigarettes.

Women. The trends among women are similar but less pronounced than those seen for men because the overwhelming majority (77\%) of women smoke filtered cigarettes. Among these filter cigarette smokers, more than $60 \%$ smoke brands with blond tobacco. Nonetheless, as educational attainment increased, so did the proportion of women who smoked blond filtered cigarettes $(39.3 \%$, among women with 1-6 years of schooling to $43.5 \%$ for those with 15 or more years of education). Among the nonfiltered brands, $12 \%$ of women smokers specifically smoked Gauloises nonfilters, compared with $39.1 \%$ of male smokers. As years of schooling increased, a steady decrease was seen in the proportion of women who smoked nonfiltered cigarettes, in general.

\section{Occupation and Filter Use}

Choice of filter and tobacco type also varied considerably by occupational status. Among male smokers, nonfiltered Gauloises were preferred by $54 \%$ of unskilled workers who smoked, but only by $29 \%$ of male professionals and execu- 


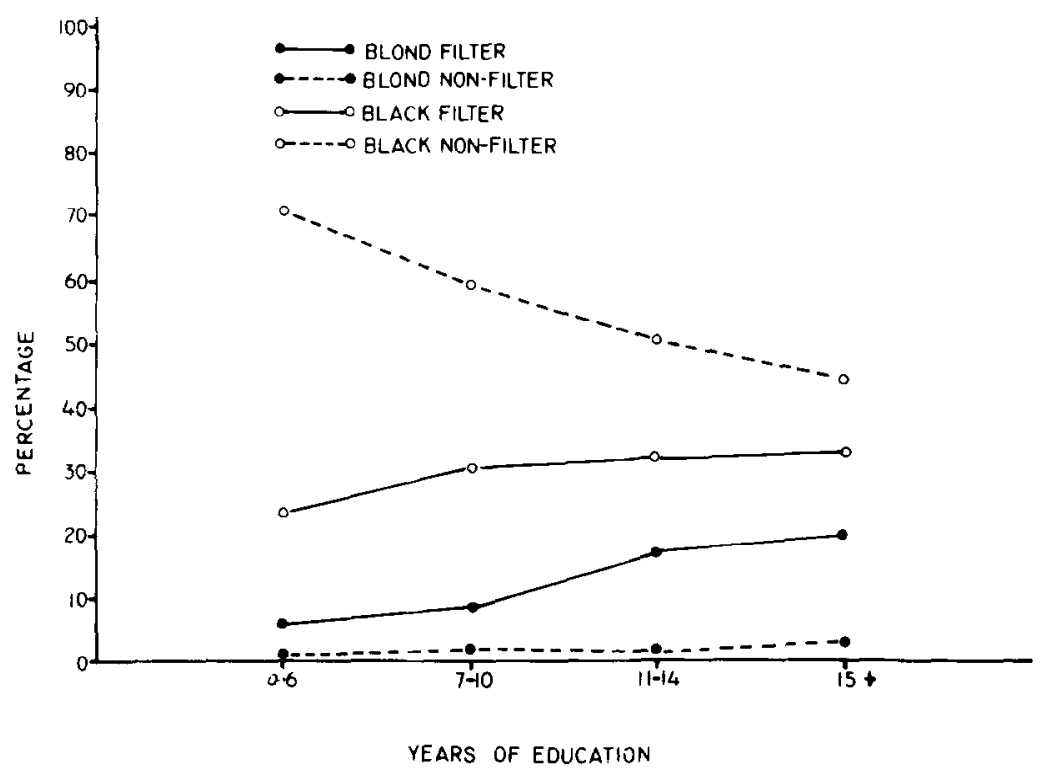

FIG. 2. Tobacco type and filter preferences among French males by education.

tives. Of this latter group, $25 \%$ smoked the more expensive blond nonfilter brands, compared with $6 \%$ of the unskilled workers who did so.

Women who were either professional or business executives, or whose husbands were, preferred blond filter cigarettes to Gauloises nonfilters (54 versus $12 \%$ of smokers), while women in the unskilled category showed the same preference, but to a lesser degree ( 38 versus $15 \%$ ).

\section{Corn Paper (Papier Mais)}

Smokers were asked whether they ever used papier mais, a slow-burning wrapper. Only $6.3 \%$ of male smokers, and $0.7 \%$ of female smokers had ever used it. Usage was noticed mostly in smokers above age 40 .

\section{Inhalation}

In accord with reported inhalation patterns in the United States and United Kingdom, men on the whole inhaled more deeply than women and twice as many women than men ( 31 versus $16 \%$, respectively) claimed not to inhale. A noteworthy difference in ages of noninhalers between men and women is demonstrated in Fig. 3. As in other countries, the proportion of noninhalers increased with age for both men and women, and the reverse was true for deep inhalers.

The amount of inhalation reported by French smokers in this study is compared in Table 4 with that reported in British and American studies $(9,18)$. While responses to questions on inhalation must be viewed guardedly because of their subjective nature, the questions in the U.S. study were identical to those used in the French study and, therefore, the results should be comparable. The majority of men who smoked nonfilter black cigarettes inhaled less than male nonfilter smokers in Britain or America. A possible explanation for this is that the smoke is 


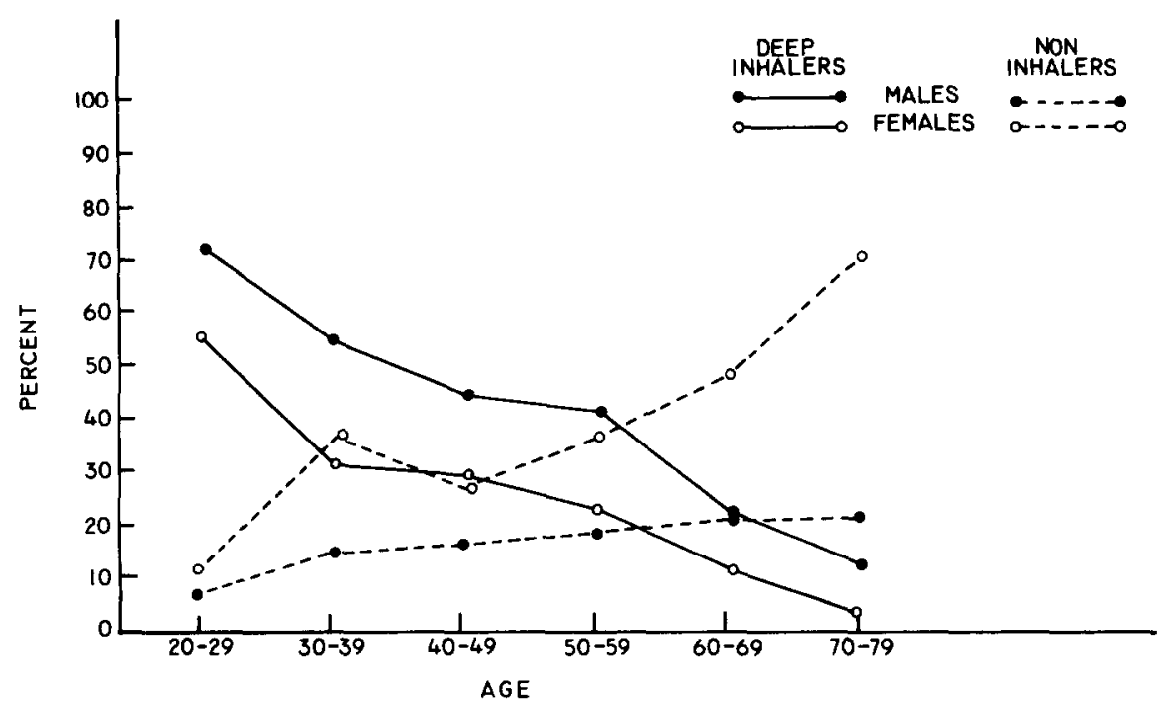

FIG. 3. Inhalation practices of French men and women, by age, 1976.

less acidic than either blended American cigarettes or English variety cigarettes. Under conditions of high $\mathrm{pH}$, a significant fraction of the nicotine is unprotonated, and therefore, more easily absorbed through the oral mucosa $(1,2)$. Thus, a French smoker of black nonfiltered cigarettes may not need to inhale as deeply in order to achieve a "satisfying" blood level of nicotine.

The difference in inhalation patterns between the blond and black filtered brands is a reflection of the younger smoking habits, i.e., proportionately more young smokers smoke filter cigarettes and proportionately more young smokers inhale the smoke. For both sexes, proportionately more smokers of black filtered cigarettes inhaled the smoke deeply into the chest.

\section{Drooping}

In contrast to Americans, many French smokers hold the lit cigarette in the mouth without inhaling the mainstream smoke. It is known that sidestream smoke (that combustion product diffusing into the air directly from the main fire without passing through the cigarette) can contain more toxic components than the mainstream (2). The frequency of the "drooping" habit was asked and the answers differed markedly between men and women. Fewer than half of the men (42.2\%) and three-quarters of the women (75.3\%) never held the cigarette in their mouths without puffing on it. One-third of the male smokers responded than such as the case "half" to always, compared with $11 \%$ of the women. The frequency of this "drooping" habit increased with age among males with no such trend apparent among the women (Fig. 4).

Of major epidemiologic interest is the fact that not only do inhalation and "drooping" practices vary with age, but they also vary in opposite directions. That is, "drooping" is a habit of the older male smokers (as in the use of corn paper, which greatly facilitates this habit), and this habit diminishes the amount of 
WYNDER ET AL.

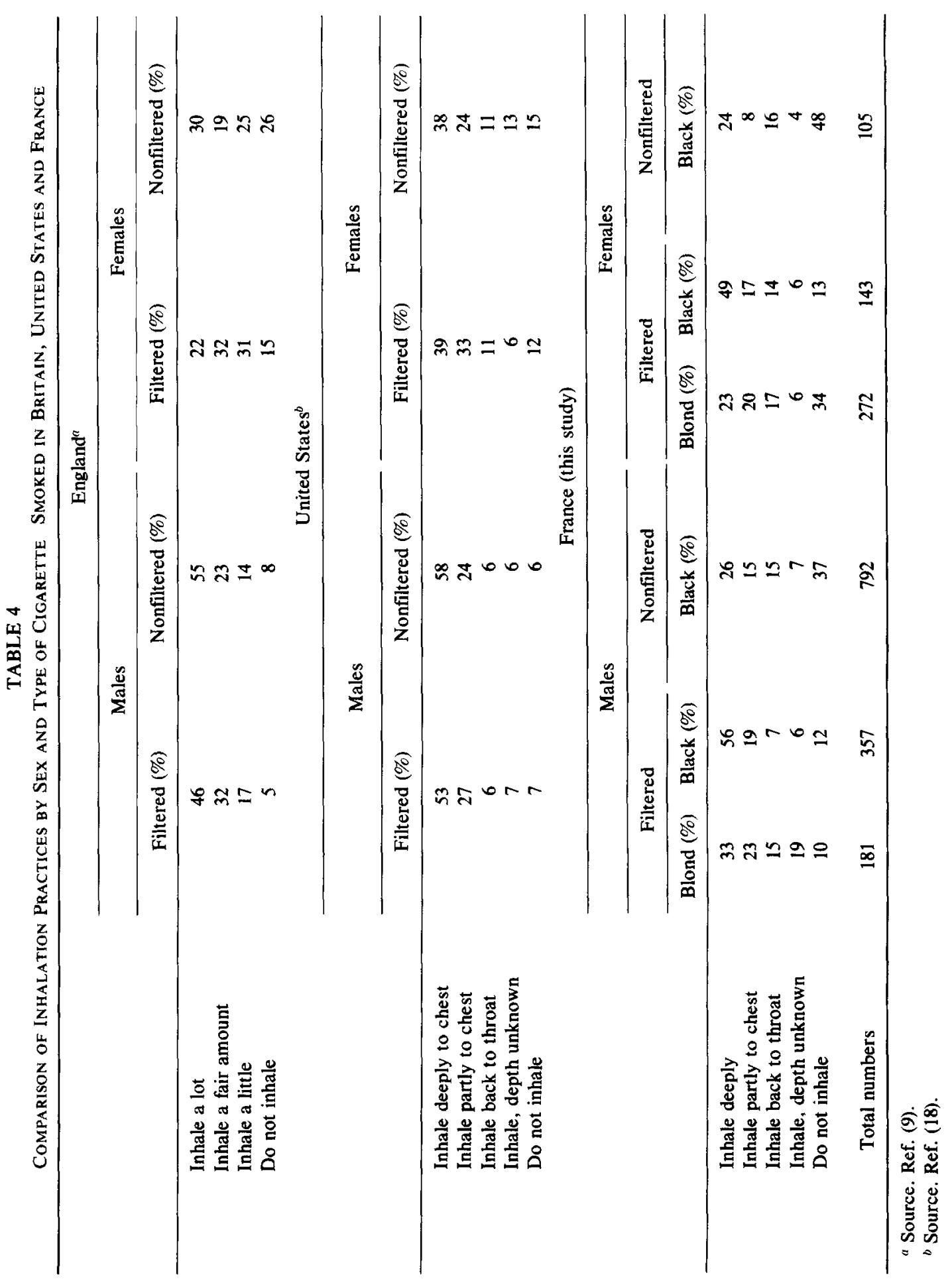




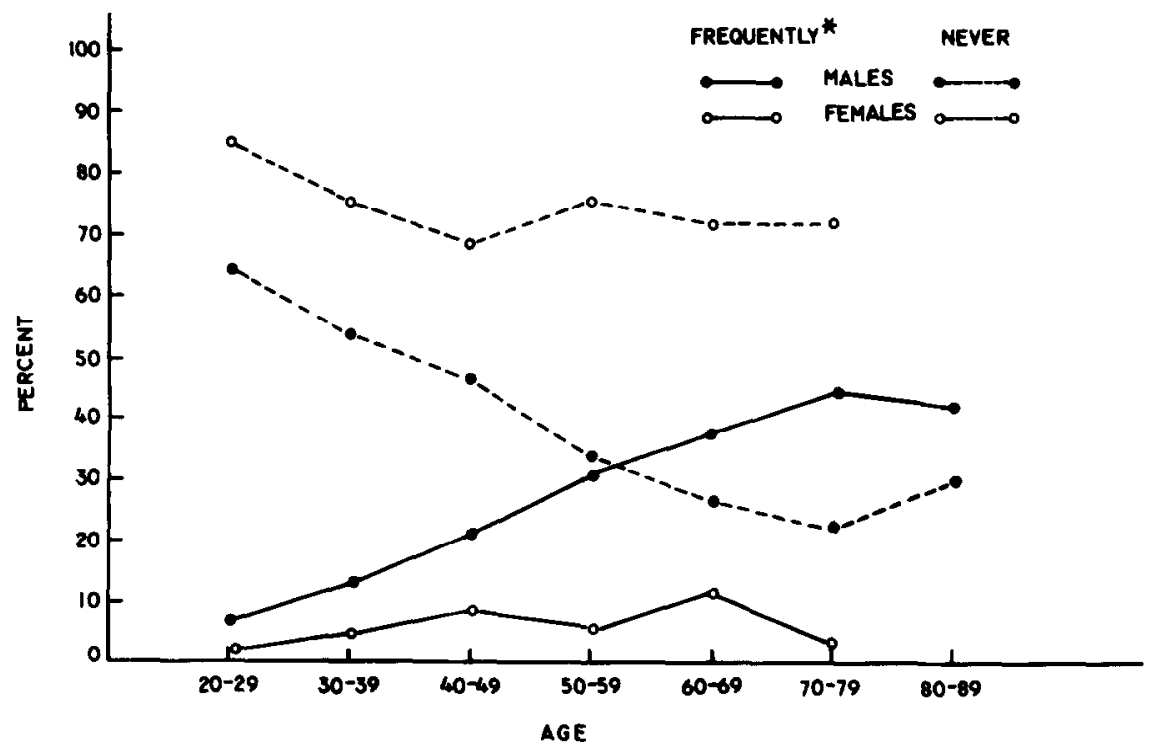

* always or more than half the time

FIG. 4. Cigarette "drooping" practices among French men and women, by age, 1976.

mainstream inhalation. Because women have relatively recently become major users of tobacco products, however, their smoking habits are more similar to those of the women in the United States and their younger male counterparts.

\section{Alcohol Consumption}

The use of alcohol in conjunction with tobacco is known to increase the risk of cancers of the mouth, larynx, and esophagus (18). These survey data confirm the stereotype that wine is the most frequently consumed alcoholic beverage in France (Table 5) among men and nonsmokers. Some additional, nontabulated data

TABLE 5

Beverage Consumption by Smoking Habit

\begin{tabular}{|c|c|c|c|c|c|c|c|c|}
\hline \multirow[b]{3}{*}{ Alcohol } & \multicolumn{4}{|c|}{ Males } & \multicolumn{4}{|c|}{ Females } \\
\hline & \multicolumn{2}{|c|}{ Nonsmoker } & \multicolumn{2}{|c|}{$\begin{array}{l}\text { Long-term } \\
\text { smoker }\end{array}$} & \multicolumn{2}{|c|}{ Nonsmoker } & \multicolumn{2}{|c|}{$\begin{array}{l}\text { Long-term } \\
\text { smoker }\end{array}$} \\
\hline & $N$ & $\%$ & $N$ & $\%$ & $N$ & $\%$ & $N$ & $\%$ \\
\hline Wine only & 123 & 41 & 409 & 34 & 207 & 36 & 101 & 26 \\
\hline Wine and beer & 22 & 7 & 91 & 7 & 8 & 1 & 17 & 4 \\
\hline Wine and liquor & 47 & 16 & 317 & 26 & 68 & 12 & 82 & 21 \\
\hline Liquor or beer & 18 & 6 & 71 & 6 & 56 & 10 & 52 & 14 \\
\hline All three & 20 & 7 & 191 & 16 & 11 & 2 & 21 & 5 \\
\hline Never drink & 71 & 24 & 140 & 11 & 220 & 39 & 120 & 31 \\
\hline Total & 301 & & 1219 & & 570 & & 393 & \\
\hline
\end{tabular}

$a \geqslant 10$ years. 
are of interest: the highest proportion of nondrinkers was found among recent smokers, $39 \%$ of whom said they did not drink any alcoholic beverages regularly. This group is almost entirely below 30 years of age. After recent smokers, nonsmokers had the largest proportion of nondrinkers (24\%). But $41 \%$ of nonsmokers drank wine (alone), and $71 \%$ of them drank wine whether alone or in combination with beer and/or liquor. This is in contrast to Americans, among whom a much stronger correlation between smoking and drinking has been found.

Local variations in alcohol consumption may also account for variation of alcohol-related cancers within France. Table 6 contrasts the alcohol consumption patterns between Manche, a largely rural area in Brittany, and Paris, and shows a marked increase, in the former, of not only liquor consumption, but also usage of all three types of alcoholic beverages. Manche and neighboring Calvados have very high rates of esophagus cancer, and are also regions of much higher consumption of alcoholic cider and certain other beverages than Paris $(13,14)$.

\section{Epidemiologic Considerations}

The present study has concerned itself with the epidemiology of some smokingrelated variables in France. While the percentage of nonsmokers does not differ much among the United States, United Kingdom, and France, there are considerable differences in inhalation, "drooping," and drinking practices among older men and women in France $(3,7,13,14)$. It is possible that the lesser inhalation practices in older French men are the result of the high $\mathrm{pH}$ of French black tobacco, which yield a larger amount of free nicotine, and thus contribute to a lesser likelihood of deep inhalation. Also, the habit of "drooping," which is relatively common among older men in France, makes deep inhalation less likely, although possibly increasing passive inhalation of sidestream smoke. We suggest that the lesser degree of inhalation and the greater proportion of "drooping" and alcohol drinking among older Frenchmen are factors associated with low rates of lung cancer and high rates of esophagus, larynx, and oral cavity cancer.

Prolonged exposure of oral cavity and esophageal tissue caused by the retention of the cigarette in the mouth with the increased exposure to sidestream smoke could account for the international differences in these mortality rates. The

TABLE 6

Alcohol Consumption Patterns in

Manche (RURal) and Paris (Urban)

\begin{tabular}{lrrrr} 
& \multicolumn{2}{c}{ Manche } & \multicolumn{2}{c}{ Paris } \\
\cline { 2 - 5 } & $N$ & $\%$ & $N$ & $\%$ \\
\hline Wine only & 11 & 17.7 & 73 & 28.6 \\
Wine and beer & 2 & 3.2 & 22 & 8.6 \\
Wine and liquor & 5 & 8.1 & 39 & 15.3 \\
Liquor and beer only & 2 & 3.2 & 23 & 9.0 \\
All three & 31 & 50.0 & 35 & 13.7 \\
Nondrinker & 11 & 17.7 & 63 & 24.7 \\
$\quad$ Total & 62 & & 255 & \\
\hline
\end{tabular}

a Includes alcoholic cider. 
fivefold difference in laryngeal cancer rates between France and the United States is also associated with tobacco usage in conjunction with alcohol consumption.

The fact that among French women the rates of these four cancers do not correspond with those of the French men, lends further support to the above possibilities. Not only do women have less tobacco and alcohol exposure but deep inhaling and "drooping" is encountered far less frequently among women. It is suggested that these practices could account for the noted sex differences in tobacco-related diseases.

The higher nitrate content of black tobacco may also affect the reported lower lung cancer rates in France since experiments indicate that tars obtained from higher nitrate tobacco cigarettes have a reduced tumor yield in mouse skin (6). It is significant that nitrate levels of American cigarettes have been rising in recent years, during the period of decline in tar and nicotine. It also appears that these cancer rates have not been increased detectably by the higher nitrosamine content of French tobacco which occurs as a consequence of the high nitrate content. In animals, some nitrosamines have been found to be organ specific for the esophagus-a finding which might also apply to man and thus contribute to increased rates of esophageal cancer. It is reasonable to assume that tobacco and/or tobacco smoke are the sources of the initiating carcinogenic stimuli, and that alcohol (ethanol) facilitates the reactivity of some tobacco-associated initiator. But clearly such a relationship does not obtain for the lung and, therefore, cannot be associated with the low rates of lung cancer in France.

These data confirm the results of other studies which implicate the higher total alcohol intake in France, in the development of cancer of the upper alimentary tract, particularly in line with the fact that alcohol has been shown to significantly enhance the development of these cancers in smokers (18). Furthermore, we may conjecture that if tobacco smoke is inhaled less, more smoke is retained within the upper alimentary tract and may thus contribute to the reported higher rate of upper alimentary tract cancers in France.

In France, as in other countries, both smoking habits and the cigarettes themselves have changed over the years. Table 7 shows changes in the tar and nicotine levels of French, British, and American cigarettes, both filter and nonfilter, over a 15 -year period $(9,10,14)$. The decrease in tar, even in nonfilter cigarettes, as well as the increased preference in all three countries for filter cigarettes is likely to have an ameliorating effect on lung cancer rates. A lower lung cancer risk among smokers of low-tar cigarettes has been noted in the United States by Hammond (5) as well as our group (16). On the other hand, reduced tar and nicotine levels might lead to an increase in deep inhalation of the smoke, and thus counteract some of this reduction in rates of tobacco-related diseases. Finally, the rapid rise in the proportion of French women who smoke may cause a rise in their lung cancer rates, as seen in the United States and England $(4,10)$

\section{CONCLUSION}

The lower rate of lung cancer in France, as compared with England and the United States, is associated with the lesser extent of inhalation among older French smokers and the greater prevalence of "drooping" the cigarettes. The 
TABLE 7

Average Tar and Nicotine Content of French, British, ANd American Cigarettes, 1960-1976

\begin{tabular}{lcccccc}
\hline & & \multicolumn{2}{c}{ Tar (mg) } & & \multicolumn{2}{c}{ Nicotine } \\
\cline { 3 - 4 } \cline { 6 - 7 } & Year & Filter & Nonfilter & & Filter & Nonfilter \\
\hline France & 1960 & 23 & 29 & & 1.8 & 2.5 \\
England & 1965 & 29 & 35 & & 2.0 & 2.2 \\
United States & 1960 & 23 & 34 & & 1.4 & 1.9 \\
& & & & & 1.0 & \\
France & 1976 & 14 & 24 & & 1.3 & 2.5 \\
England & 1975 & 17 & 25 & & 1.1 & 1.6 \\
United States & 1976 & 17 & 26 & & & \\
\hline
\end{tabular}

Source. Refs. $(9,10,14)$.

higher rate of oral cancer in France compared with these two countries is consistent with the high consumption of alcohol in France, and the fact that proportionately more older French men hold the lit cigarette in the mouth for extended periods of time.

Younger French smokers inhale more and "droop" less than older smokers, perhaps as a consequence of lower tar and nicotine levels in newer French cigarettes. It remains to be determined whether the future rates of tobacco-related cancers in France will become more like those of the United States and United Kingdom as the French adopt more comparable smoking habits. That is, it seems possible to predict that not only will the sex differences in rates diminish but also that the mortality rates for lung cancer will increase (while those of larynx, esophagus, and oral cavity might decrease). Continued monitoring of tobaccorelated diseases in France in relation to cigarette consumption is in order.

\section{ACKNOWLEDGMENTS}

We wish to thank the following persons for their valuable assistance in administering the questionnaires: Michel Froidevaux, Victor Marengo, Phillippe Dard, Phillippe Girault, Jean Pierre Huc, Herve Juille, Jean Lepagno, Pierre Lerminet, Marie Louise Lorillot, Stephan Thorn, Gilles Vuillierme.

\section{REFERENCES}

1. Armitage, A. K., and Turner, K. M. Absorption of nicotine in cigarette and cigar smoke through the oral mucosa. Nature (London) 226, 1231-2332 (1970).

2. Brunnemann, K. D., and Hoffmann, D. The $\mathrm{pH}$ of tobacco smoke. Food Cosmetol. Toxicol. 12, 115-21 (1974).

3. Department of International Economic and Social Affairs, Statistical Office. "Demographic Yearbook." 29th issue (1977). United Nations, New York, 1978.

4. Doll, R. Surveillance and monitoring. Int. J. Epidemiol. 3, 305-314 (1974).

5. Hammond, E. C., Garfinkel, L., Seidman, H., and Lew, E. A. Tar and nicotine content of cigarette smoke in relation to death rates. Environ. Res. 12, 263-274 (1976).

6. Hoffmann, D. Unpublished data.

7. International Labor Office. "1979 Yearbook of Labour Statistics," 29th issue. United Nations, Geneva, 1980.

8. Ledez, P. Personal communication.

9. Lee, P. N. (Ed.) "Statistics of Smoking in the United Kingdom, Research Paper I," 7th ed. Tobacco Research Council, London, 1976. 
10. Levin, D. L., Devesa, S. S., Godwin, J. D., and Silverman, D. Cancer Rates and Risks," 2nd ed. U.S. DHEW Publ. (NIH) 76-691, 1976.

11. Segi, M., and Kurihara, M. "Cancer Mortality for Selected Sites in 24 Countries, No. 6, 1966-1967." Japan Cancer Society, Nagoya, 1972.

12. Simmonnet, D., Pourquoi fumez-vous? L'Express 58-60, July 21-27, 1979.

13. Tuyns, A. J. Cancer of the esophagus: Further evidence of the relation to drinking habits in France. Int. J. Cancer 5, 152-156 (1970).

14. UNESCO, "1978-1979 Statistical Yearbook," UNESCO, France, 1980.

15. Wynder, E. L., and Hecht, S. S. (Eds.) "UICC Technical Report Series," Vol. 25, Chap. 6. UICC, Geneva, 1976.

16. Wynder, E. L., Mushinski, M., and Stellman, S. D. The epidemiology of the less harmful cigarette. "Smoking and Health. I. Modifying the Risk for the Smoker" (E. L. Wynder, D. Hoffmann, and G. B. Gori, Eds.), pp. 1-12. U.S. Govt. Printing Office, Washington, D.C., 1976.

17. Wynder, E. L., and Mushinski, M. H. Epidemiology of smoking habits and prospects for reduction in risk for sub-populations of smokers. In preparation.

18. Wynder, E. L., and Stellman, S. D. Comparative epidemiology of tobacco-related cancers. Cancer Res. 37, 4608-4622 (1977). 